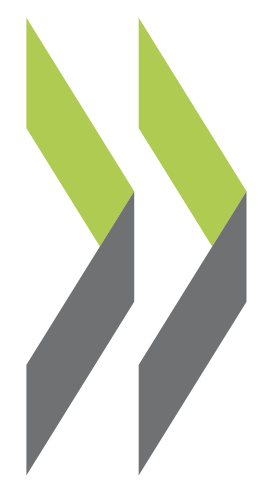

OECD Trade and Environment Working Papers 2011/04

Trade-Related Measures Based on Processes and Production Methods in the Context of ClimateChange Mitigation

Evdokia Moïsé, Ronald Steenblik 


\section{OECD TRADE AND ENVIRONMENT WORKING PAPERS}

The OECD Working Paper series is designed to make available to a wide readership selected studies by OECD staff or by outside consultants.

This document has been declassified on the responsibility of the Joint Working Party on Trade and Environment under the OECD reference number COM/TAD/ENV/JWPTE(2010)5/FINAL.

Comments on the papers in this series are welcome and should be sent to env.contact@oecd.org or tad.contact@oecd.org.

OECD TRADE AND ENVIRONMENT WORKING PAPERS

are published on www.oecd.org/trade and www.oecd.org/environment

(C) OECD 2011

Applications for permission to reproduce or translate all or part of this material should be made to: OECD Publishing, rights@ oecd.org or by fax to +33145249930. 


\title{
Abstract \\ TRADE-RELATED MEASURES BASED ON PROCESSES AND PRODUCTION METHODS IN THE CONTEXT OF CLIMATE-CHANGE MITIGATION
}

\author{
by \\ Evdokia Moïsé and Ronald Steenblik
}

This paper provides an overview of existing measures relating to non-product-related processes and production methods (PPMs) adopted in the context of climate-changemitigation policies, especially those linked to the life-cycle greenhouse-gas (GHG) emissions of particular products. Such domestic PPM-related requirements and schemes are important policy tools for promoting sustainable development and are aimed at addressing GHG emissions resulting from the activities involved in producing, processing and transporting the product to the final consumer. Their ostensive purpose is to promote better environmental outcomes and to ensure that domestic climate-change policies and incentives do not inadvertently undermine other environmental objectives. Even though the general objectives of the reviewed regulations and private schemes are comparable (e.g. the promotion of renewable-energy sources, or provision of information on the carbon footprint of goods), the approaches, level of detail, choices of instruments and targeted environmental characteristics vary considerably from country to country and from scheme to scheme. Some regulations rely more or less extensively on market mechanisms, attaching price premiums to certain types of products. Others introduce command-and-control provisions limiting the use of certain PPMs, variously defined in different countries. Still others target certain types of fuels eligible for public support, with varying eligibility criteria. Private schemes mainly use environmental sustainability claims to secure consumer preference. The choice of different instruments presumably entails different trade impacts. However, all of the reviewed measures and schemes are fairly new, and experience with their application and therefore their potential trade effects has so far been relatively limited.

JEL classification: F13, F18, N50, Q56

Keywords: processes and production methods, environmental provisions, trade and environment, trade policy.

\section{Acknowledgements}

The report was written by Evdokia Moïsé and Ronald Steenblik of the OECD Secretariat, under the direction of Dale Andrew, Head of the Trade Policy Linkages Division of the OECD Trade and Agriculture Directorate. The authors are grateful to the delegates to the Joint Working Party on Trade and Environment for their comments and suggestions. The views expressed in the paper do not necessarily reflect the official views of the OECD nor of the governments of its member countries nor those of the European Union. 


\section{Table of contents}

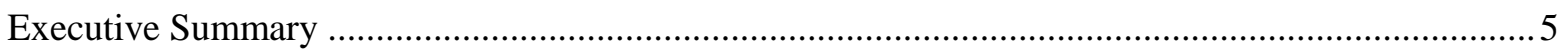

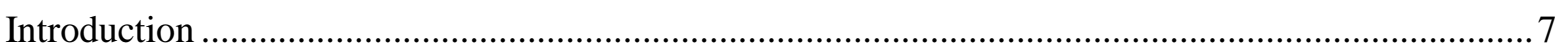

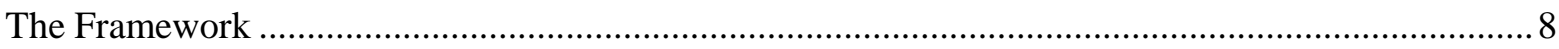

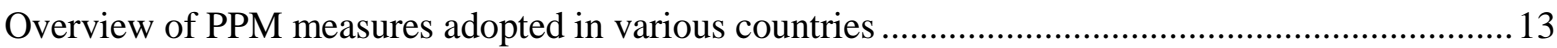

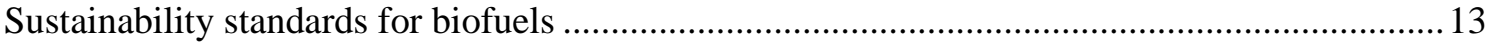

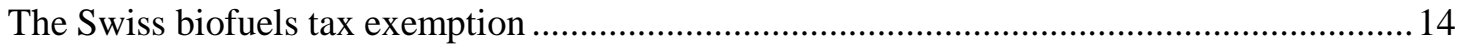

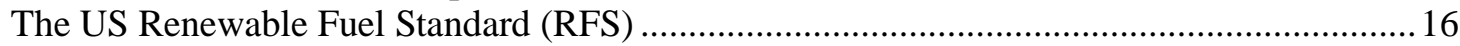

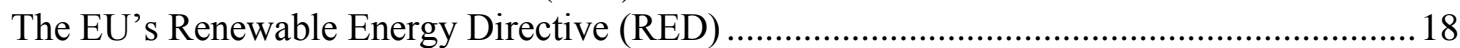

The UK's Renewable Transport Fuel Obligation Programme (RTFO) .................................2

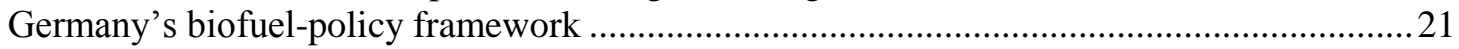

Non-governmental initiatives to promote standards for "sustainable" biofuels .......................22

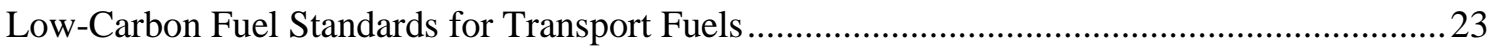

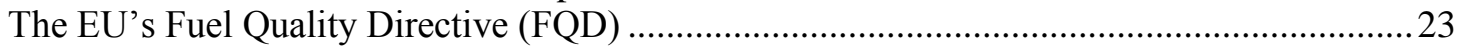

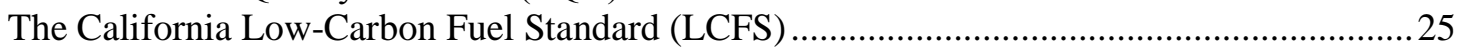

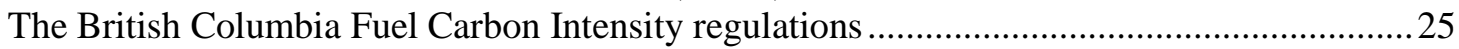

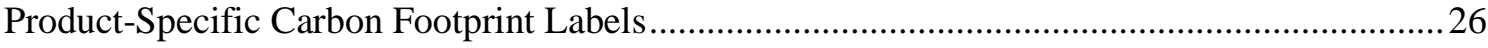

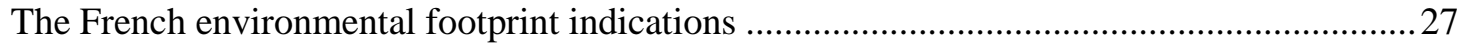

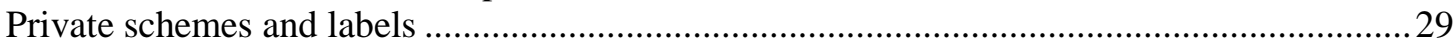

Preferences in Government Procurement Relating to Life-Cycle Environmental Impacts...........34

The US preference for procurement of alternative fuels ............................................................34

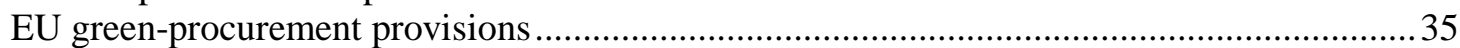

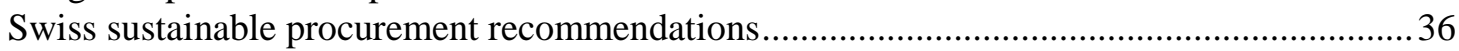

Carbon Footprint Requirements in Corporate Supply-Chain Schemes........................................37

An example of requirements in corporate supply chain schemes:

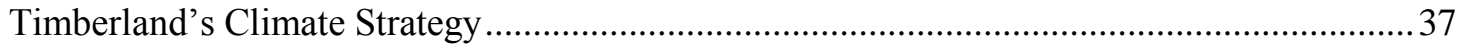

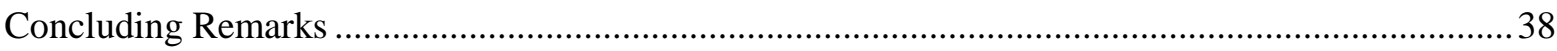

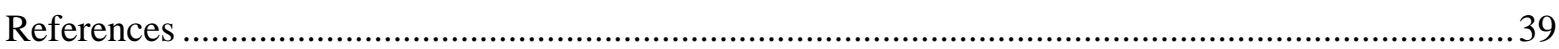




\section{List of Abbreviations}

$\begin{array}{ll}\text { ADEME } & \text { Agence de l'Environnement et de la Maîtrise de l'Énergie } \\ & \text { [France's Environment and Energy-Management Agency] } \\ \text { AFNOR } & \text { Association Française de Normalisation [the French Standards Association]. } \\ \text { BLCAO } & \text { Biofuels Life-Cycle Assessment Ordinance [Switzerland] } \\ \text { CAD } & \text { Canadian dollar } \\ \text { CO }_{2} & \text { carbon dioxide } \\ \text { EPA } & \text { Environmental Protection Agency [United States] } \\ \text { EU } & \text { European Union } \\ \text { FOEN } & \text { Federal Office of the Environment [FOEN] } \\ \text { FQD } & \text { Fuel Quality Directive [European Union] } \\ \text { GHG } & \text { greenhouse gas } \\ \text { GBP } & \text { British pound sterling } \\ \text { ISO } & \text { International Organization for Standardisation } \\ \text { LCA } & \text { life-cycle assessment } \\ \text { LCFS } & \text { low-carbon fuel standard } \\ \text { MinOTO } & \text { Mineral Oil Taxation Ordinance [Switzerland] } \\ \text { OECD } & \text { Organisation for Economic Co-operation and Development } \\ \text { PAS } & \text { Publicly Available Specification [United Kingdom] } \\ \text { PCF } & \text { product carbon footprint } \\ \text { PPM } & \text { processes and production method } \\ \text { RED } & \text { Renewable Energy Directive [European Union] } \\ \text { RFS } & \text { Renewable Fuel Standard [United States] } \\ \text { RFS2 } & \text { Renewable Fuel Standard, Version 2.0 [United States] } \\ \text { RIN } & \text { Renewable Identification Number [United States] } \\ \text { RSB } & \text { Roundtable on Sustainable Biofuels } \\ \text { RSPO } & \text { Roundtable on Sustainable Palm Oil } \\ \text { RTFC } & \text { Renewable Transport Fuel Certificate [United Kingdom] } \\ \text { RTFO } & \text { Renewable Transport Fuel Obligation [United Kingdom] } \\ \text { RTRS } & \text { Round Table on Responsible Soy Association } \\ \text { RVO } & \text { Renewable Volume Obligation [United States] } \\ \text { SMEs } & \text { small and medium enterprises } \\ \text { USD } & \text { United States dollar } \\ & \end{array}$




\section{Executive Summary}

The objective of this study is to provide an overview of existing measures relating to non-product-related processes and production methods (PPMs) adopted in the context of climate-change-mitigation policies and strategies and in particular those linked to the greenhouse-gas (GHG) emissions of the resulting products. It describes public and private climate-change-mitigation policies and strategies that were designed to target environmental impacts during the full lifecycle of a product, including its production and processing phase, considering the fact that GHG emissions result in global climate-change impacts irrespective of where they are generated.

Domestic PPM-related requirements and schemes are important policy tools for promoting sustainable development. In respect of action to mitigate climate change, such PPM-related policy measures are aimed at addressing GHG emissions generated during the production, processing and transport of products. The general objective is to promote more environmentally sound activities and to ensure that domestic climate-change policies and incentives do not inadvertently undermine other environmental objectives. Moreover, consumers in many countries are increasingly seeking information on how the PPMs of the products they buy affect the environment, and this has led to the emergence of various public and private initiatives involving GHG accounting and labelling.

Conceptually, PPM measures can be categorised on the basis of the environmental impacts they seek to address. When the PPM does not affect the physical characteristics of the resulting product, but creates environmental impacts at the production and processing stage only (non-product related PPMs), a number of technical and legal issues may arise for international trade. These can be explored by examining whether implemented or proposed measures or requirements are transparent, predictable, feasible, and their effects on trade.

The transparency of domestic measures is understood as the capacity of regulated entities to express views on, identify, and understand their commitments and obligations under the rule of law, and refers to the clear, participatory and accountable character of policy and rule-making and standard setting. Predictability provides stakeholders with the means to accurately assess potential costs, risks and market opportunities and implies consistent and coherent interpretation and enforcement. The feasibility of PPM measures refers to the capacity of regulated economic operators to cope with the measures and of the concerned authorities to enforce them. The measures can be distinguished in terms of their technical, economic and legal feasibility, relating, respectively, to the existence of reliable testing and verification techniques, the cost of verification and certification systems and the consistency of the measures with applicable rules of domestic or international law. Finally, the trade impact of particular PPM measures can be assessed by reference to the effects on trade of 
measures that efficiently achieve the policy objective. The relevance of the above characteristics for private initiatives can be considered mutatis mutandis.

The development in the future of internationally agreed criteria for assessing the GHG emissions and other sustainability characteristics of products such as biofuels might help overcome feasibility problems and reduce related costs for governments and the private sector. As in other policy areas, the transparent and participatory elaboration of applicable requirements would contribute to their effectiveness and acceptability and help avoid capture by vested interests. A balance should be found between including criteria that are quantifiable and verifiable and leaving enough flexibility to account for specific conditions in different producing regions.

An initial overview of existing climate-change mitigation regulations and voluntary standards reveals that provisions focussing on non-product-related PPMs exist in a number of climate-change regulations, but are not widespread in the majority of them. Most of these provisions introduce life-cycle sustainability standards for biofuels covering the way the associated biomass has been grown and the fuel produced. The standards are defined and calculated in quite a different manner in various countries. Fewer PPM requirements focus on lifecycle GHG-emission characteristics for transport fuels more generally. Mandatory carbon-footprint labels for a wide range of consumer products are only now in the process of being elaborated, although several voluntary schemes have already been developed. Preferences in government procurement relating to lifecycle environmental impacts are sometimes envisaged by purchasing entities. Climate-related voluntary schemes elaborated and implemented by the private sector are gradually gaining ground, although there is still much work underway to refine supporting databases and assessment methods.

Even though the general objectives are comparable across the reviewed regulations and private schemes (including promotion of renewable energy sources, while seeking to avoid other harmful consequences on the environment; and provision of information on the carbon footprint of goods), the approaches, level of detail, choices of instruments and targeted environmental characteristics vary considerably from country to country and from scheme to scheme. Some regulations rely more or less extensively on market mechanisms, attaching price premiums to certain types of products. Others introduce command-and-control provisions limiting the use of certain PPMs, variously defined in different countries. Other regulations target certain types of fuels for financial or regulatory support, there again with varying eligibility criteria. Private schemes mainly use environmental sustainability claims to secure consumer preference. The choice of different instruments presumably entails different trade impacts. However, all of the reviewed measures and schemes are fairly new and experience with their application and potential trade effects is therefore relatively limited. 


\section{Trade-Related Measures Based on Processes and Production Methods in the Context of Climate-Change Mitigation}

\section{Introduction}

The recognition of climate change as a major global environmental challenge has driven policy makers to adopt an array of climate-change-mitigation policies. In addition to "flexibility mechanisms" provided under the Kyoto Protocol, such as greenhouse-gas emissions trading, joint implementation and the Clean Development Mechanism, countries have started implementing domestic climatechange measures as described in Article 2 of the Kyoto Protocol. These include enhancement of energy efficiency in relevant sectors of the national economy; (...) promotion, development and increased use of new and renewable forms of energy, of carbon dioxide sequestration technologies and of advanced and innovative environmentally sound technologies; progressive reduction or phasing out of (...) fiscal incentives, tax and duty exemptions and subsidies in all greenhouse gas emitting sectors that run counter to the objective of the Convention and application of market instruments; measures to limit and/or reduce emissions of greenhouse gases (...) in the transport sector; and limitation and/or reduction of methane emissions through recovery and use in waste management, as well as in the production, transport and distribution of energy. Parties to the Kyoto Protocol have agreed that domestic policies and measures will "constitute a significant element of the effort made by each Party" to meet its commitments.

Given the global character of climate change, an increasing number of the domestic measures adopted to date are designed so as to target environmental impacts during the life-cycle of a product, including its production and processing phases. This is irrespective of whether the activities that have climate impacts occur inside or outside the territory of the regulating country. The focus on lifecycle considerations results from the policy objective to promote more environmentally sound activities, to reduce global emissions of GHGs and to reduce the risk that domestic climate-change policies and incentives might result in activities which damage the environment in other ways. Indeed, in the absence of life-cycle considerations, policies aimed at, for instance, incentivising the use of certain fuels could result in higher overall emissions. In addition, policy makers need to be concerned not to undermine other equally important environmental objectives, such as the conservation of biodiversity, as an unintended consequence of policies to reduce GHG emissions. Moreover, consumers in many countries are increasingly seeking information on how the production of the products they buy affects the environment, and this has led to the emergence of various public and private initiatives on GHG accounting and labelling. 
Policies targeting adverse environmental impacts created in foreign lands as a result of producing goods for export have long been quite timid, but are now gaining prominence in the climate-change debate for the above reasons. The objective of this study is to provide an overview of existing measures relating to non-product-related processes and production methods (PPMs) ${ }^{1}$ adopted in the context of climate-change mitigation policies and in particular those linked to the greenhouse-gas emissions of the resulting products.

The paper elaborates on an analytical framework of transparency, predictability, feasibility and trade impact, ${ }^{2}$ and what it would mean in practice. It then provides a descriptive and factual overview of measures that have been adopted by various countries, noting their coverage, classification under the conceptual framework and other relevant characteristics. The overview covers both mandatory government measures and a representative sample of climaterelated voluntary schemes elaborated and implemented by the private sector. The paper does not analyse the feasibility, effectiveness and efficiency of the described measures nor does it discuss their policy implications and the challenges raised by their design and implementation.

\section{The Framework}

PPM-based trade-related instruments include direct regulation (command and control), such as import or export restrictions on products not conforming to certain PPM requirements; public authorities' market-based interventions or economic instruments, such as fiscal measures, environmental charges, taxes or subsidies, border-tax adjustments and countervailing duties; and attempts to enable informed consumer choice that could in turn influence production patterns (environmental labelling schemes).

PPMs whose environmental impacts arise only or primarily at the production and processing stage and which do not affect the physical characteristics of the resulting product (non-product related PPMs), raise a number of issues for international trade. How to assess the conformity of imported products with applicable PPM requirements? And what is the status of these requirements with regard to the provisions of international law? Non-product related PPMs can be analysed based on the degree to which the environmental impact they produce affects other countries or shared resources. Non-product-related PPMs can have trans-boundary or global effects, including:

(1) trans-boundary pollution;

(2) effects on migratory species and shared living resources;

(3) global concerns;

1. Extended producer responsibility (EPR) provisions, conferring to the producer physical or economic responsibility for the recovery, recycling or disposal of the product, could also be viewed as PPM requirements.

2. One such early attempt to address this was the 1997 OECD paper, Processes and Production Methods (PPMs): Conceptual Framework and Considerations on Use of PPMbased Trade Measures, OECD/GD(97)137. 
or can be felt solely within the country of origin:

(4) environmental and other effects limited to the territory of the country applying the PPM.

Category 3, covering PPM requirements addressing global environmental concerns, such as those related to climate change, calls for action by all (or at least a significant number of countries) to ensure effective management of the environmental issue at stake. Co-ordinated action through an international environmental agreement could help spread the burden of internalising environmental externalities among concerned parties. However, when there is no such international agreement or undertaking, the question is how to pursue environmental objectives while taking account of the trade impacts.

Generally speaking, current trading rules do not distinguish among traded products based on criteria that are not physically embodied in the products (i.e. the PPM requirements addressing production externalities). The framework used here subjects domestic measures to an examination of whether implemented or proposed measures or requirements are transparent, predictable, feasible, and have an impact on trade. An additional criterion, the effectiveness of reviewed measures in achieving their policy objectives, might help further fine-tune policymakers' choices in the area of climate change, and could also inform actions by the private sector. The notions of transparency, predictability, feasibility and trade effect are to a large extent inspired by the basic concepts in the multilateral trading system, although assessing PPM requirements against these notions in no way prejudges the requirements' consistency with WTO rules.

The transparency of domestic measures adopted by public authorities is understood as the capacity of regulated entities to express views on, identify, and understand their obligations under the rule of law (OECD, 2001). For policy makers and administrations, transparency offers a remedy against inadequate information in the public sector, especially in highly technical policy areas such as climate-change mitigation. It helps ensure that proposed requirements appropriately take into account local conditions and activity-specific circumstances, and effectively address the environmental issue at stake. Transparent policy making also reinforces the capacities of governments to implement policy effectively, because informed stakeholders are better prepared and more willing to support implementation, thus improving compliance prospects. For the regulated entities, transparency helps ensure that the proposed requirements are clear, adequately understood and accepted by stakeholders. Transparency is also relevant for private voluntary requirements and schemes, to the extent that they affect marketing opportunities - or, in some cases, such as biofuel sustainability standards or carbon-footprint labels - are accepted as a means to prove compliance with mandatory schemes. However, the specific modalities for ensuring transparency of private requirements would logically differ from those applying to public regulatory activities, and would also depend on the nature of the private scheme at stake (e.g. collective or company-specific).

The transparency of domestic measures needs to be assessed in various phases of the regulatory process or the development of standards and voluntary schemes (Moïsé, 2011). In the pre-establishment phase of laws, regulations and standards, transparency entails the timely announcement of planned legislative, regulatory and standard-setting initiatives as a means of providing concerned entities with 
advance notice of forthcoming requirements in the market. In the design phase, the publication of draft laws, regulations and standards, and associated public consultations provides firms time and flexibility to adjust to regulatory changes and helps identify and address unintended obstacles to trade so as to fend off unnecessary burdens on economic activity. Information should be made available when the administration's, or the standardising body's, reflection is sufficiently mature to provide preliminary analysis and enable an effective and informed dialogue on the issues being consulted on. At the same time, participatory transparency mechanisms have to intervene at a sufficiently early stage as to be able to influence the administration's, or the standardising body's, policy choices.

In the adoption phase, information on how the administration or standardising body has considered and incorporated stakeholder input and on the rationale of final policy and regulatory choices reinforces the accountability of the body as regards policy choices and reduces the risk of capture by vested interests. Plain language drafting is also an important criterion, especially considering the growing complexity and technical nature of regulation, which may significantly increase compliance costs. In the implementation phase, the transparency of regulatory measures and policy choices should be judged also on account of the accessibility of information, not only in terms of material access conditions but most importantly in terms of the clear, intelligible and comprehensive character of information, including related environmental and trade-impact assessments and relevant underlying technical analysis and data. Sharing with consulted entities the impact assessment undertaken by the administration on the basis of expert information and previous stakeholder feedback enhances their capability to understand the issues at stake and start preparing for compliance.

At the same time, transparency considerably reinforces the predictability of the business environment, by providing stakeholders with the means to accurately assess potential costs, risks, and market opportunities. When an importing country or company wishes to subject imported goods to measures or conditions related to a process or production method in the country of origin, this shifts part of the economic impact of the measure to non-nationals. Domestic market players as much as foreign traders and investors seeking access to a market need to base economic decisions on accurate assessments of potential costs, risks, and market opportunities.

The predictability of domestic measures relies to a great extent on their consistent and coherent interpretation and enforcement. Difficult and complex criteria for meeting climate-change-mitigation requirements and intricate administrative procedures for assessing and demonstrating conformity with such requirements may result in varying interpretations and create uncertainties as to the enforcement of applicable requirements. Economic operators' obligations are more difficult to anticipate and prepare for when they are linked to evolving factors rather than scheduled in advance. As a separate issue, diverging PPM requirements in various countries, or even distribution chains, and the distortions stemming from the resulting market segmentation may also create uncertainty and translate into high compliance costs for economic operators. The development of widely recognised frameworks for sustainability standards could provide a valuable basis for reliable and predictable implementation. 
The feasibility of domestic climate-change-mitigation measures refers to the capacity of economic operators to cope with the measures and of the concerned authorities to enforce them. In the case of non-product-related PPM measures, it concerns more particularly the capacity to meet and enforce measures that are not related to the physical characteristics of the goods. Three types of feasibility can be distinguished: technical (including administrative), economic and legal. Technical feasibility relates, among other factors, to the availability and practicality of testing techniques and raises the problem of identifying and monitoring the PPM used. Where detection at the border is technically impracticable, as is the case for non-product-related PPMs, the observance of PPM requirements needs to be verified by on-site inspection, monitoring and certification of the production process in the exporting country, or self-certified by the concerned producer or importer.

This raises issues of administrative feasibility as it calls for measurable, reasonably precise and well-defined indicators and is a complicated task, not only from a logistical point of view. Environmental sustainability standards incorporating climate-related criteria are still at their early stages of development, to a large extent within the framework of corporate and NGO initiatives to establish certification schemes for biofuels and related feedstock. Within these schemes, criteria referring to GHG emissions or macro-level effects, such as domestic food security and competition with other applications, effects on global commodity prices and resulting effects on purchasing power of different groups, are much less developed. The latter are particularly difficult to assess, as effects may be felt outside the area of production or consumption, across borders, and even reach global dimensions.

The economic feasibility of non-product-related PPM measures concerns the cost of verification and certification systems, both as regards economic operators and the entities administering the measures or private schemes. The costs of proving compliance with established sustainability criteria, for instance through certification, increase the costs of meeting the criteria themselves. The costs will be highly dependent on the number, strictness and inclusiveness of the criteria established by the system. They will vary with the scale of the production company, and be disproportionally borne by smaller companies if there are no collective arrangements, as PPM verification and certification entails a certain amount of fixed costs, not connected to the produced or imported volumes. Producers and exporters in developing countries may also face special difficulties, because of deficient conformity assessment and certification infrastructure in those countries.

Extra-jurisdictional verification would be greatly facilitated and related costs contained if it were based on bilateral or multilateral agreements or arrangements on verification and certification systems, or on the mutual recognition of existing domestic systems. For instance, such systems could be supported by standards ISO 14064 and ISO 14065, recently developed by the International Organization for Standardisation (ISO), setting an internationally agreed private voluntary framework for measuring GHG emissions and verifying claims made about them, to the extent that reliance on such norms would guarantee the achievement of the objectives pursued by each measure or scheme. 
Finally, the legal feasibility of non-product-related PPMs is connected to the applicable rules of domestic or international law, including provisions of domestic competition law or on advertising claims (particularly in the context of private schemes) and relevant provisions or decisions of the WTO, multilateral environmental agreements or regional trade agreements. The question of whether a particular non-product-related PPM requirement is consistent with WTO disciplines or qualifies under an exception to those disciplines would depend on the specificities of the individual case. In so far as private schemes are concerned, international law requirements applying to State action would obviously not be applicable.

The trade impact of domestic measures refers to the effect on trade of measures that efficiently achieve a given policy objective (such as climate change mitigation, or more specifically increased use of biofuels, or consumer information on the carbon footprint of goods). Like feasibility, the trade impact should be considered both from the point of view of the administration's capacity to enforce and monitor the measures and from the perspective of the regulated entities that need to comply with them. It can be viewed as a parallel or even overlapping notion to the economic feasibility as far as costs of implementation are concerned. An assessment of the trade effects of a measure does not question the environmental policy objectives but only considers its impact on trade, its cost-efficiency and its administrative feasibility, nor does it assess the environmental effectiveness of domestic measures or standards. "Effectiveness" should be defined within the context of climate change mitigation where such PPM-related trade measures would form part of the package of policy mechanisms used to reduce GHG emissions.

Differing PPM formulations may have different impacts, particularly on trade, the cost effectiveness of such requirements or the latitude they allow for technological innovation. There are two ways of formulating a PPM-based requirement: one singles out specific PPMs to be used to the exclusion of any other, e.g. by specifying that regulated products should be produced according to one or several defined technologies. This approach risks favouring technologies that are unavailable, unsuitable or prohibitively expensive for trading partners. The other would leave free choice as to the PPM that will actually be used, either by prohibiting one or several PPMs which are to be avoided - but allowing the use of any other - or by specifying the emission or performance effects which are meant to be avoided or achieved. The transparent and participatory elaboration of applicable requirements would help avoid capture by vested interests. Balance should be found between including criteria that are quantifiable and verifiable and leaving enough flexibility to account for specific conditions in different producing regions.

Even where more flexible market-based interventions are preferred over command-and-control regulations, the categorisation according to source, type or characteristics set by the policy maker to support a fiscal or incentives structure may have significant trade consequences. This is true not only for governmentmandated instruments, but also for PPM-based requirements implemented through voluntary schemes by industry. Like a number of government instruments that do not inhibit trade for products not conforming to their PPM-based requirements, but nevertheless affect market conditions for those products through their provisions on subsidies or credit, voluntary schemes may influence 
considerably the market share of targeted products. ${ }^{3}$ Their potential to affect market access for targeted products could be assessed by applying the above framework mutatis mutandis.

\section{Overview of PPM Measures Adopted in Various Countries}

Among the types of non-product related PPMs that exist or have been proposed by governments and that address GHG emissions produced outside the country importing the affected products are: (a) sustainability standards for biofuels; (b) low-carbon-fuel standards for transport fuels; (c) product-specific carbon footprint labels; and (d) preferences in government procurement relating to life-cycle environmental impacts. An initial, quite extensive but not exhaustive, review by the Secretariat shows that most of the GHG-emissions-related regulations containing PPM-based requirements correspond to the first category: regulations introducing sustainability standards for biofuels. The approaches, level of detail, choices of instruments and targeted environmental characteristics can vary significantly from country to country, despite presumably similar regulatory objectives. On the other hand, voluntary schemes elaborated and implemented by the private sector mainly belong to the third category (productspecific carbon footprints and related certification and labels). A fifth (e) category would include carbon-footprint requirements imposed on productive input suppliers by private corporate supply chains.

\section{Sustainability standards for biofuels}

This group includes government measures requiring that biofuels meet minimum levels of reduction in life-cycle GHG emissions, compared with the petroleum products they replace, in order to qualify towards domestic regulations mandating the use of specific volumes of biofuels or benefit from subsidies or excise-tax exemptions (see de Gorter and Just, 2009; Zarrilli and Burnett, 2009) and related sustainability standards, often elaborated outside the government. The fuel industry is a heavily regulated industry all over the world, with products subject to many technical regulations in every country. Unlike agricultural commodities, which generally face high market entry barriers, oil and other energy products (with the notable exception of fuel ethanol) traditionally face low entry barriers but high regulatory barriers. These product-related regulations and standards include technical specifications for fuel, relating to their physical and chemical properties and emission standards for fuel and vehicles. To these product-related regulations, recent climate-change mitigation policies have added PPM-based standards requiring the measurement of GHG life-cycle emissions. They generally take the form of measurable sustainability criteria and a series of minimum quantitative or qualitative indicators to establish whether a given product meets the criteria. These provisions are to a certain extent supported by non-governmental initiatives to develop biofuel sustainability standards that include environmental, social and economic principles and criteria, and related

3. Note that the (unadopted) 1991 Tuna-Dolphin WTO Panel report (United States Restrictions on Imports of Tuna, DS21/R, 39S/155, paragraph 5.42) found that the voluntary scheme under review did not prevent tuna products from being sold freely with or without the "dolphin-safe" label and that any advantage that occurred was due to consumer choice. 
third-party certification. It is noteworthy that a Biofuels Sales Obligation introduced by New Zealand in 2008 was subsequently repealed because it was felt that the moment was not ripe for implementation before biofuel sustainability standards were put in place in the country. ${ }^{4}$

\section{The Swiss biofuels tax exemption}

Amendments to the Swiss regulatory framework for mineral-oil taxation were introduced in 2008 with the objective of reaching Switzerland's target on $\mathrm{CO}_{2}$ emissions by promoting biofuels that satisfy minimum environmental and social standards. The new framework, based on the Mineral Oil Taxation $\mathrm{Act}^{5}$ (MinOTA) and Ordinance ${ }^{6}$ (MinOTO) and the Biofuels Life-Cycle Assessment Ordinance $^{7}$ (BLCAO) exempts fuels produced from renewable feedstock from the mineral oil tax, provided that they prove they have a positive aggregate environmental impact and are produced under socially acceptable conditions. In order to qualify for the exemption, manufacturers or importers need to provide information on the entire process of production, transportation and distribution of the products, so as to allow the Federal Office of the Environment (FOEN), the Federal Customs Administration and the State Secretariat for Economic Affairs (SECO) to establish the aggregate environmental impact of the product through environmental life-cycle assessment (LCA) and an assessment of its potential threats to biodiversity. Information provided by the applicant is balanced against impact data in the Ecoinvent ${ }^{8}$ and other equivalent databases based on the ecological-scarcity method or other equivalent methods. ${ }^{9}$

Biofuels covered by the exemption include ethanol, biodiesel, biogas, biomethanol, dimethyl bio-ether, biohydrogen, synthetic biofuels and vegetable or animal oils used for fuel. Mixes of fossil fuels with any of the above may benefit from a proportional tax relief. The Federal Council determines annually the quantity of biofuels eligible for the exemption on the basis of a number of considerations, including their contribution to energy-policy objectives and their relative price compared with fossil fuels. Exemptions are attributed on a first-request, first served basis until the annual quantity determined by the Federal Council has been covered. Attributed tax reliefs and exemptions are valid over a period of four years, unless the prerequisite conditions are no longer satisfied.

Minimum life-cycle emission requirements in order to qualify for the exemption are set at $40 \%$ less GHG than the life-cycle emissions of the fossilfuels that the biofuels replace. In addition, fuels from renewable sources should not harm the environment significantly more than fossil fuels and should not endanger tropical forest preservation and biological diversity. The MinOTO sets a

4. www.beehive.govt.nz/release/biofuel+obligation+law+repealed

5. 641.61 of 21 June 1996, as amended on 23 March 2007.

6. 641.611 of 20 November 1996, as amended on 30 January 2008.

7. $\quad 641.611 .21$ of 3 April 2009 .

8. $\quad$ www.ecoinvent.ch

9. See Federal Office for the Environment FOEN, The Ecological Scarcity Method: EcoFactors 2006 - A method for impact assessment in LCA. 
positive and a negative presumption: biofuels obtained from residues or wastes of agricultural or forestry production or processing are presumed to fulfil those conditions if they were produced using the latest available technologies; producers need not provide specific proof of their positive environmental impact. On the other hand, biofuels from palm oil, soybeans or cereals are presumed not to fulfil the above conditions, but the applicant can provide evidence to prove that they do. The MinOTO does not seek to impose Swiss social-regulation preferences as regards the minimum requirements on socially acceptable conditions of production. These requirements are satisfied if the cultivation of raw materials and production of fuel have respected at least the fundamental conventions of the International Labour Organization (ILO), or the social regulations applicable in the producing country.

Beyond these presumptions the burden of proof lies with the producer or importer to provide information on the type, description and quality of fuel; on the entire process of fuel production, from cultivation of raw materials to the distribution of fuel to the consumers; and on their impact on tropical forests and biodiversity. The producer or importer must provide information on the production process and in particular on:

- the cultivation of the raw materials (the quantitative and economic yield of the raw materials and of the wastes and by-products they generate, crop rotation, cultivation and harvesting technology - including the use of machines and energy sources - the nature and quantity of fertilizers and phytosanitary products used, and the irrigation technology used and quantity of water consumed;

- the manufacturing of the fuel (fuel manufacturing technology, type and quantity of energy and other inputs used, products and by-products obtained and wastes generated during manufacturing, the energetic and economic yield of products and by-products, waste disposal, and GHGs and pollutants generated); and

- the transport of the fuel (transformation sites, transport means and distances between the cultivation site and the consumer distribution sites).

If the production of the biofuel benefits the environment by promoting biodiversity, increasing soil fertility, or protecting non-renewable water resources, the applicant can present related information in order to support his application.

In order to allow assessment of the impact on tropical forests and biodiversity, the producer or importer also needs to indicate the source of the raw materials and identify and describe the cultivation site and previous uses of that site; provide information about environmental provisions applicable in the production zone and their enforcement; and attest to the use of good practices for cultivation, harvesting, crop rotation, soil quality protection and plant choice.

The applicant must provide documentation that proves the accuracy of the information. Being responsible for the assessment of the proof of the positive aggregate environmental impact, the FOEN may demand, in doubtful cases, that independent third parties verify and confirm the accuracy of the information. The BLCAO provides for the recognition of equivalence of relevant third-country regulations or recognised national or international standards, thus potentially 
relieving imported biofuels from duplicative proof requirements. The applicant must provide evidence that the biofuels have been produced in accordance with such regulation or standard and enclose the related texts so as to enable the FOEN to assess their partial or full equivalence with the Swiss ecological balance requirements.

\section{The US Renewable Fuel Standard (RFS)}

The National Renewable Fuel Standard Program (RFS programme) was mandated by the US Congress and implemented by the US Environmental Protection Agency (EPA) in order to promote the use of renewable fuels in the transportation sector. The aim was to reduce greenhouse-gas emissions and improve air quality, while decreasing dependence on fossil-fuel imports and diversifying the country's energy portfolio. The RFS programme was initially introduced by the Energy Policy Act of 2005 (EPAct) and subsequently amended by the Energy Independence and Security Act of 2007 (EISA). PPM regulations under the amended programme (RFS2) entered into effect in 2011.

By virtue of the RFS programme, road-transport fuel sold or imported into the United States every year must contain a minimum volume of renewable fuel. This Renewable Volume Obligation (RVO), borne by fuel producers (refiners, blenders) and importers is calculated as a percentage of the total fossil fuel amount they put on the US market. Compliance with the RVO for each producer or importer is judged "at the refinery gate", i.e. after the fuel has been produced or imported and before it has been delivered to retail outlets or wholesale purchasers or consumers. Obligated parties calculate their RVO on the basis of the Renewable Fuel Standard that the EPA sets each year in November for the upcoming year based on projected next-year gasoline consumption and the renewable volume requirements in the Energy Bill.

The RFS2 programme introduces significantly higher volumes of renewable fuels ( 36 billion gallons of biofuels by 2022, almost a five-fold increase over the original target for 2012) and categorises renewable fuels into four different types:

- renewable biofuel: fuel that is produced from renewable biomass and that is used to replace or reduce the quantity of fossil fuel present in transportation fuel;

- advanced biofuel: renewable fuel, other than ethanol derived from corn starch; ${ }^{10}$

- cellulosic biofuel: renewable fuel derived from any cellulose, hemicellulose or lignin that is derived from renewable biomass; and

- biomass-based diesel: renewable fuel that is biodiesel as defined in the EPAct.

10. This could include ethanol derived from cellulose, hemi-cellulose, or lignin, ethanol derived from sugar or starch other than corn starch, ethanol derived from waste material, including crop residues, other vegetative waste material, animal waste, and food waste and yard waste, biomass-based diesel, biogas and butanol or other alcohols produced through the conversion of organic matter from renewable biomass, and other fuel derived from cellulosic biomass. 
The categorisation allows for the introduction of specific sustainability criteria for different products, by imposing different life-cycle emission reduction standards (at least 20\% of GHG reduction for renewable fuels, $50 \%$ for advanced biofuels and biomass-based diesel, and $60 \%$ for cellulosic biofuels). The calculation of GHG reduction is based on a life-cycle emission assessment, including direct emissions and significant indirect emissions such as those resulting from land-use change, and including all stages of fuel and feedstock production and distribution, from feedstock generation or extraction through the distribution, delivery and use by the ultimate consumer, adjusting values to account for the relative global warming potential of the gases emitted.

Batches of renewable fuels are assigned Renewable Identification Numbers (RINs) by their producers or importers. The RINs are used to demonstrate compliance with the RFS and are transferred with the corresponding renewable fuel batch, thus playing the role of credit currency for the RFS programme. Producers or importers that fail to blend the required amount of renewable fuel to meet their RVO obligation need to acquire credits for this amount, in the form of RINs. RIN supply and demand as determined by the regulatory obligations generated by the Act define the market price of renewable fuel batches. In addition to the federal RFS mandate, a number of state blending mandates and even municipal mandates are in effect, many of which have the force of law.

The administration is required to report to Congress on the current and future effects of these measures, including imports. In order to assess these effects the administration was obliged to develop basic sustainability criteria, which were not as such included in the legislation. This involved the development of standards and best-management practices for resource development, production and extraction and verification by means of certification. The National Academy of Sciences was invited to consider the likely impact on feed for domestic livestock, and policy options for alleviating that impact, while maintaining regional agricultural and silvicultural capacity. In this review it sought input from a number of stakeholders, such as producers of feed grains, of livestock, poultry and pork products, of food and food products, of energy, producers and users of biomass feedstock, users and consumers of renewable fuels and people interested in conservation, environment and nutrition issues.

In addition to the provisions promoting the use of renewable fuels, the regulation introduces labelling requirements, in order to support informed consumer choice. Retail diesel fuel pumps have to be labelled in a manner that informs consumers of the percent of biomass-based diesel or biodiesel that is contained in the blend offered for sale. Specific labelling requirements will be enacted by the Federal Trade Commission. 
The EU's Renewable Energy Directive (RED)

The European Union introduced legislation to promote electricity produced from renewable energy sources in 2001 and to promote biofuels and other renewable fuels for transport in 2003. ${ }^{11}$ It adopted further provisions in $2009^{12}$ enforcing mandatory targets of a $20 \%$ share of energy from renewable sources in overall EU energy consumption and a $10 \%$ minimum target for the share of renewable energy (including biofuels in transport by 2020). The 2009 Renewable Energy Directive (RED) covers all types of energy from renewable non-fossil sources: wind, solar, aerothermal, geothermal, hydrothermal and ocean energy, hydropower, biomass, landfill gas, gas from sewage treatment plants and biogases. In addition, it establishes sustainability criteria for biofuels and bioliquids (liquid fuel for energy purposes other than transport), irrespective of whether the raw materials were grown inside or outside the territory of the Union.

Member States are required to meet varying national targets of energy from renewable sources so as to contribute to an overall EU consumption target of $20 \%$ by 2020. In parallel, each Member State has to ensure by 2020 that the domestic energy consumption in transport is supplied at least $10 \%$ by renewable energy. Member States have established national renewable-energy action plans, so as to facilitate among other things the transfer of energy from renewable sources between countries that expect excess production and countries with insufficient production.

The primary sustainability criterion in the Directive is a GHG emission saving compared with fossil fuel of at least 35\%, brought to 50\% from 2017 onwards and to $60 \%$ from 2018 onwards for biofuels produced in newly launched installations. This is the only criterion that biofuels produced from waste and residues must meet. ${ }^{13}$ For other biofuels, additional criteria relate to the protection of land biodiversity and the preservation of land with high carbon stock. Raw materials used to produce biofuels should not be obtained from land that had a high biodiversity value in January 2008, including: (a) primary forest and other wooded land hosting native species and ecological processes not significantly disturbed; (b) areas designated for nature protection purposes, or for the protection of rare, threatened or endangered ecosystems or species, unless evidence is provided that their production does not interfere with these purposes; (c) highly biodiverse grasslands. Furthermore, raw materials used to produce biofuels should not be obtained from land that had high carbon stocks in January 2008 , including wetlands and continuously forested areas with significant canopy cover, or from peatland, unless evidence is provided that the cultivation and harvesting does not involve drainage of previously undrained soil.

11. Directive 2001/77/EC of the European Parliament and of the Council of 27 September 2001 on the promotion of electricity produced from renewable energy sources in the internal electricity market. Directive 2003/30/EC of the European Parliament and of the Council of 8 May 2003 on the promotion of the use of biofuels or other renewable fuels for transport.

12. Directive 2009/28/EC of the European Parliament and of the Council of 23 April 2009 on the promotion of the use of energy from renewable sources and amending and subsequently repealing Directives 2001/77/EC and 2003/30/EC.

13. With the exception of agricultural, aquaculture, fisheries and forestry residues. 
Agricultural raw materials cultivated in the European Union and used to produce biofuels should also comply with EU environmental requirements for agriculture. Although such criteria do not apply to imports from third countries, under the Directive the EU is to encourage the development of multilateral and bilateral agreements and voluntary international or national schemes that cover key environmental and social considerations, in order to promote the production of biofuels and bioliquids worldwide in a sustainable manner. Only biofuels that comply with sustainability criteria count against biofuels targets and renewableenergy obligations, and are eligible for financial support for the consumption of biofuels and bioliquids.

Beyond the environmental sustainability criteria described above, the Directive introduced no social criteria or criteria relating to macro-level effects. However, the Commission will report every two years to the European Parliament and Council on the impact of increased demand for biofuel on social sustainability in the European Union and in third countries, on the availability of foodstuffs at affordable prices, especially in developing countries, and on the respect of landuse rights and wider development issues and will, if necessary, propose corrective action to address food-price increases.

In order to demonstrate compliance with the sustainability criteria, the Directive advocates the use of a mass balance system, whereby consignments of raw material or biofuel with differing sustainability characteristics can be mixed, the resulting mixture considered to have the same sustainability characteristics as the sum of all consignments added in the mixture. Other verification methods can be contemplated in the future, provided they maintain the effectiveness and integrity of the verification system without imposing an unreasonable burden on industry. Economic operators are required to submit information on their compliance with sustainability criteria. In so far as additional environmental and social aspects are concerned (including those relating to soil, water and air protection; the restoration of degraded land; the avoidance of excessive water consumption in areas where water is scarce; and social aspects as set out in the Directive) economic operators must indicate whether the consignment has been certified or accepted as fulfilling the requirements of a voluntary scheme that has been recognised by the Commission as containing accurate data on those issues, both for biofuels produced in the European Union and for imported ones. They should arrange for independent auditing of the submitted information and provide evidence that this has been done. Data contained in voluntary national or international schemes setting standards for the production of biomass products or for measuring GHG savings could be used for these information-provision purposes, if they are judged accurate by the Commission following review of the schemes' reliability, objectivity, transparency and independent auditing.

In addition to the provisions promoting the use of renewable fuels, the Directive introduces consumer information requirements, in order to support informed consumer choice. The percent of biofuels that is contained in the blend offered for sale should be indicated in retail fuel sale points where this percentage exceeds $10 \%$ by volume. 


\section{The UK's Renewable Transport Fuel Obligation Programme (RTFO)}

The K's Renewable Transport Fuel Obligation Programme (RTFO) was introduced in 2007 in order to meet the objectives established by the EU 2003 Biofuels Directive. Since April 2008, the RTFO has placed an obligation on fuel suppliers to ensure that a certain percentage of their aggregate sales of road transport fuel are made up of biofuels. Fuel companies were required to sell a minimum of 2.5\% renewable transport fuels in FY 2008/09 (i.e. the year ending 31 March 2009), increasing gradually to 5\% from April 2013 onwards. The Programme includes a reporting framework covering both the net GHG savings and the sustainability of biofuels. Targets set by the UK government for 2008/09 were: (a) $50 \%$ of renewable fuel characteristics reported, (b) $40 \%$ annual GHG savings from supplied fuel, and (c) $30 \%$ of feedstock meeting a qualifying environmental standard. By year three $(2010 / 11)$, the data-capture target was $90 \%$, the target for GHG savings was $50 \%$, and the target for fuels meeting a qualifying environmental standard was $80 \%$. According to the RTFO Quarterly Report 11, which covers the period 15 April 2010 through 14 January $2011^{14}$, the rate of reporting of both the feedstock and the country of origin during the ninemonth period was $95 \%$; a GHG savings of $55 \%$ was achieved ${ }^{15}$; and $49 \%$ of the biofuels met a qualifying environmental standard.

Where requirements have been met the UK Department for Transport (DFT) ${ }^{16}$ issues a Renewable Transport Fuel Certificate (RTFC) to transport fuel suppliers for each litre of qualifying fuel. When it was first introduced, on 1 April 2008, there was a fuel duty of GBP 0.271 per litre on all road-transport fuels, but a rebate of GBP 0.20 per litre for biofuels. The duty and rebate continued at these rates in 2009/10. From 1 April 2010, the GBP 0.20 per litre rebate was restricted only to biodiesel made from used cooking oil; this rebate is intended to be scrapped in April 2012. From that point, biofuels produced from UCO will earn twice the RTFCs of other biofuels for an equivalent volume. The aim has been to reward biofuels in accordance with the carbon-equivalent savings that they offer from April 2010 onwards, and from April 2011 onwards to reward biofuels only if the feedstocks from which they are produced meet appropriate sustainability standards. RTFCs are transferrable from suppliers with surplus RTFCs to suppliers with insufficient renewable fuel supply. Suppliers that fail to meet their RTFO obligation even through RTFC purchases are required to pay a buy-out penalty. This penalty was set initially at GBP 0.15 per litre for $2008 / 09$, increased to GBP 0.35 per litre in 2009/10, and reduced to GBP 0.30 per litre in 2010/11. ${ }^{17}$

14. www2.dft.gov.uk/pgr/statistics/datatablespublications/biofuels/latest/rtfoqtrly11.pdf.

15. This figure may not include all emissions from direct land-use change and excludes the emissions from indirect land-use changes.

16. Originally the RTFO was administered by a non-departmental public body, the Renewable Fuels Agency (RFA). On 31 March 2011 the RFA was dissolved and its duties were transferred to the DFT.

17. For further information see the DFT's website, www.dft.gov.uk/topics/sustainable/biofuels/rtfo/. 


\section{Germany's biofuel-policy framework}

The German 2007 Biofuel Quota Act introduced a quota for a minimum addition of biofuels to petrol and diesel in Germany and empowers the government to establish sustainability criteria for biofuels that are eligible to participate in the quota system. Following this, and in response to the EU Renewable Energy Promotion Directive, a Biomass Flow Sustainability 2009 $\operatorname{Order}^{18}$ set a series of sustainability criteria, including the protection of land with high natural value, high carbon stocks, peatland, and sustainable agriculture, which will be used for entitlement to remuneration. An International Sustainability and Carbon Certification (ISCC) system was developed with the financial support of the Ministry for Food, Agriculture and Consumer Protection.

\section{Non-governmental initiatives to promote standards for "sustainable" biofuels}

Existing certification schemes from corporate and NGO initiatives, such as the Roundtable on Sustainable Biofuels (RSB), the Roundtable on Sustainable Palm Oil (RSPO), or the Roundtable on Responsible Soy Association (RTRS), have developed criteria for assessing the sustainability of biofuels and related feedstock, especially in the forestry and agricultural sector, although work to develop indicators for assessing compliance with the criteria is still in progress.

The RSB is an international initiative co-ordinated by the Energy Center at $\mathrm{EPFL}^{19}$ in Lausanne that brings together farmers, companies, non-governmental organisations, experts, governments, and inter-governmental agencies concerned with ensuring the sustainability of biofuels production and processing. It does not directly certify products but has developed a third-party system for certififying biofuels to their sustainability standards. Participation in the RSB is open to any organisation working in a field relevant to biofuels sustainability. The RSB seeks to be recognised by regulators as the "one-stop shop" for compliance with applicable biofuel sustainability criteria.

In November 2009, the RSB released Version One of its international standard for better biofuel production and processing, including principles and criteria and an associated guidance document, detailed compliance indicators, and a glossary of terms. The principles and criteria describe the sustainability requirements with which biofuel operators have to comply ${ }^{20}$, while the certification system defines the rules to enable operators to make verifiable claims of compliance with the RSB. This system covers the entire biofuel supply chain and establishes mechanisms for chain-of-custody management, for claims and communications. Prior to the release of Version One, the RSB conducted a sixmonth public consultation on Version Zero of the draft standard, and released a number of intermediate iterations as it moved towards Version One.

18. Federal Government Order on Requirements Pertaining to the Sustainable Production of Liquid Biomass for Generating Electricity.

19. École Polytechnique Fédérale de Lausanne, Switzerland.

20. Principle 3 focuses more particularly on greenhouse-gas emissions. Other principles include legality; planning, monitoring and continuous improvement; human and labour rights; rural and social development; local food security; conservation; soil; water; air; use of technology, inputs and management of waste; and land rights. 
In 2010, the RSB Standard was field tested in several pilot projects in the Americas, Africa, Asia, and Europe, and the feedback coming from these projects was used to revise and improve the Standard, which became Version 1.1. A onemonth public consultation on Version 1.1 was conducted during September 2010, and comments were made publicly available on the RSB website. The RSB adopted Version 2 of the operational certification standard at the end of 2010 and began to issue its first compliance certificates in early 2011. However, the standard is meant to evolve, reflecting changing technical, environmental and social realities.

The primary intended use of the RSB Standard is a certification system involving independent third-party certification bodies. The system seeks to differentiate between the standard-setting, implementation and verification (i.e. certification and accreditation) functions, in order to enhance transparency and accountability and avoid conflicts of interest. Conformity with the RSB standard is self-assessed by the "participating operators" basis by independent certification bodies which audit their compliance.

The RSPO and the RTRS were both initiated by the WWF in co-operation with concerned producers and retailers and formally established in 2004. They are not-for-profit associations delivering certification for, respectively, sustainably produced palm oil and soy (not just for biofuel production), on the basis of a set of principles and criteria they elaborate. Their membership is open to all concerned stakeholders in the sector. The RSPO unites stakeholders from seven sectors of the palm oil industry: oil palm producers, palm oil processors or traders, consumer goods manufacturers, retailers, banks and investors, environmental or nature conservation NGOs, and social or developmental NGOs. The RTRS is composed of the main soy value-chain stakeholders, including producers, industry and civil-society actors. In June 2010 the RTRS issued version 1.0 of the RTRS Standard for Responsible Soy Production, including principle 4.3 on "efforts ... to reduce emissions and increase sequestration of Greenhouse Gases (GHGs) on the farm", and 4.4 on "responsible ... expansion of soy cultivation" (land-use change), alongside other criteria on environmental impacts, agricultural practices, labour conditions and relations with the local community. In June 2011 a Brazilian farm became the first to export soy certified to the RTRS standard.

The RSPO currently works ${ }^{22}$ on researching and developing definitions and criteria for the sustainable production and use of palm oil, with the objective of "promoting the growth and use of sustainable oil palm products through credible global standards and engagement of stakeholders".

21. "Participating operators" are entities or groups of entities producing, converting, processing, blending, trading, using or otherwise handing biomass or biofuels. These operators have entered an agreement with the RSB, which engages them to comply and demonstrate compliance with RSB standards and certification systems, and allows them in counterpart to make public claims about their RSB certified products.

22. Criteria for sustainable palm-oil production and the construction of measurable indicators for the various criteria are undertaken by the RSPO Standing Committee on Standards and Certification. 
The RSB and the RTRS were among seven voluntary schemes approved by the European Commission on 19 July 2011 to ensure the sustainability of biofuels. The other schemes approved were the International Sustainability and Carbon Certification (a German-government financed scheme covering all types of biofuels), Bonsucro EU (a roundtable initiative for sugarcane-based biofuels focussing on Brazil), 2BSvs (a French-industry scheme covering all types of biofuels), the Abengoa RED Bioenergy Sustainability Assurance (an industryspecific scheme for the biofuel-producing company, Abengoa, covering their own supply chain), and Greenergy (an industry-sponsored scheme for the company Greenergy, covering sugar-cane ethanol from Brazil). These recognitions apply directly in all 27 EU Member States.

\section{Low-carbon fuel standards for transport fuels}

This group includes measures that require suppliers of fuel to reduce the average emissions (usually expressed in kilogrammes of $\mathrm{CO}_{2}$-equivalent per gigajoule of energy supplied) of the fuels they supply, based on the assessed lifecycle GHG emissions of each energy source (see, e.g. Hodgson, 2008; California Air Resources Board, 2009; Sperling and Yeh, 2009). Some regulations (such as the California LCFS and the British Columbia RLCFR) base enforcement on market mechanisms attaching price premiums to lower-carbon fuels creation through the creation of regulatory "credits", while for others (the EU Fuel Quality Directive) the enforcement approach is still under development.

\section{The EU's Fuel Quality Directive (FQD)}

The European Union introduced its Fuel Quality Directive (FQD) in 1998 for health and environmental reasons, notably to reduce harmful air pollutants through the establishment of minimum specifications for transport petrol and diesel fuels. ${ }^{23}$ This regulation, aimed at supporting parallel regulation limiting pollutant emissions from road vehicles and non-road mobile machinery, was reviewed in $2009^{24}$ in order to meet the Union's GHG-emission targets under the Kyoto Protocol. Calculating that the combustion of road transport fuel is responsible for around $20 \%$ of EU greenhouse-gas emissions, the FQD seeks to reduce the life-cycle GHG emissions of these fuels.

The FQD applies to fuel used in road vehicles and non-road mobile machinery (including vessels used on inland waterways, agricultural and forestry tractors and recreational craft). Fuel suppliers are required to report the life-cycle GHG emissions of the fuel that they supply and to reduce them from 2011 onwards. The method for calculating life-cycle GHG emissions of biofuels under the FQD is the same as the one applied under the EU's Renewable Energy Directive (see above)

23. Directive 98/70/EC of the European Parliament and the Council of 13 October 1998 relating to the quality of petrol and diesel fuels.

24. Directive 2009/30/EC of the European Parliament and the Council of 23 April 2009 amending Directive 98/70/EC as regards the specification of petrol, diesel and gas-oil and introducing a mechanism to monitor and reduce greenhouse gas emissions and amending Council Directive 1999/32/EC as regards the specification of fuel used by inland waterway vessels and repealing Directive 93/12/EEC. 
and includes all relevant stages from cultivation, including direct land-use changes, transport and distribution, processing and combustion, irrespective of where these emissions occur. The issue of indirect land-use change is currently being studied. The FQD foresees adoption of implementing rules for fuels other than biofuels through a Committee procedure. The requirements of the Directive were to be transposed by Member States by means of laws, regulations and administrative provisions by 31 December 2010 at the latest.

Fuel suppliers, as designated by Member State regulation, shall report annually from 2011 onwards the GHG intensity of fuel and energy supplied within each Member State. In particular, they shall report the total volume of each type of fuel they supply and its origin, and the life-cycle GHG emissions per unit of energy (understood as the total mass of $\mathrm{CO}_{2}$-equivalent emissions, divided by the total energy content of the fuel or energy supplied). They will be required to gradually reduce, by 31 December 2020, life-cycle GHG emissions by $6 \%$ per unit of energy supplied compared with the baseline EU-average level of GHG emissions from fossil fuels in 2010. This will be achieved through the use of biofuels, alternative fuels and reductions in flaring and venting at production sites. The European Commission will report in 2012 on the achievability of a further $4 \%$ reduction in GHG intensity: $2 \%$ from the use of carbon capture and storage technologies and electric vehicles, and 2\% through the purchase of credits under the Clean Development Mechanism of the Kyoto Protocol. Suppliers may choose to associate in order to meet reduction obligations jointly.

The FQD sets default values and a method for calculating actual values for GHG emissions from biofuels that are identical to those set out in the Renewable Energy Directive. Default values may only be used for specific types of raw materials, including all raw materials cultivated outside the Union, while for all other biofuels only actual values can be used. Suppliers are free to use actual values to demonstrate that their biofuels achieve higher savings than indicated by the default values applying to them. Default values and accounting methods will be reviewed regularly, seeking to avoid uncertainty for investment and paying particular attention to methods of accounting for wastes and residues, co-products and co-generation of electricity from processing facilities. The FQD introduces the same sustainability criteria for biofuels production as the ones applied under the Renewable Energy Directive (see above) and only biofuels produced in accordance with these criteria will be considered compliant with the GHGreduction targets, whether they are produced from raw materials cultivated inside or outside the territory of the European Union. The same methods for demonstrating and verifying compliance with sustainability criteria are used as in the Renewable Energy Directive.

The Commission is to report every two years to the European Parliament and Council on the measures taken in Member States and third countries to respect the sustainability criteria. It is also to report on the impact of increased demand for biofuels on social sustainability in the Member States and third countries. The European Union is to endeavour to conclude bilateral or multilateral agreements with third countries containing provisions on sustainability criteria. Such agreements could be used as a basis for demonstrating that biofuels produced from raw materials cultivated in those countries comply with the sustainability criteria contained in the Fuel Quality Directive. 


\section{The California Low-Carbon Fuel Standard (LCFS)}

The State of California is developing sustainable bioenergy as part of its renewable fuels programme. In 2007 it proposed the establishment of the LowCarbon Fuel Standard (LCFS), a life-cycle-based GHG-emission standard for transport fuels with the aim of reducing the carbon intensity of California's transportation fuels by $10 \%$ by $2020 .{ }^{25}$ The LCFS regulation was adopted in April 2009 by the Air Resources Board (ARB), based on technical and policy analysis prepared by the University of California. Under LCFS regulations, fuel providers will be required to reduce the "carbon intensity value" of their products, understood as the equivalent amount of carbon dioxide emitted from each stage of production, transportation, storage and use of the fuel (direct GHG emissions), as well as the land use changes associated with the production and the energyefficiency of the vehicle using the fuel. The unit of measure is grams of carbondioxide equivalent per megajoule of fuel delivered to a vehicle $\left(\mathrm{gCO}_{2}\right.$-eq/MJ).

Enforcement of the LCFS is based on a system of "credits" and "deficits". Credits are generated from fuels with lower carbon intensity than that of the standard (gasoline and diesel fuel and their alternatives) measured on a life-cycle basis. Deficits result from the use of fuels with higher carbon intensity than the standard. Credits equal to, or greater than, the deficits a regulated party has incurred serve to demonstrate compliance with LCFS obligations and can be banked or traded in the LCFS market when in surplus. Credits and deficits are to be determined based on the amount of fuel sold, the carbon intensity of the fuel, and the efficiency by which vehicles convert the fuel into useable energy, for each year between 2011 and 2020 in a LCFS Compliance Schedule. Direct GHG emissions are assessed using the Greenhouse Gases, Regulated Emissions, and Energy Use in Transportation (GREET) model, modified for use in California (CA-GREET). Indirect land-use-change emissions were assessed using the GTAP global trade model. However, following questions about the appropriateness of this calculation, the ARB decided to refine and improve the analysis of indirect effects of transportation fuels, including land-use effects, and seek to formulate regulatory amendments or recommendations by 1 January 2011.

California is currently the only jurisdiction in the United States with an LCFS or similar regulation. However, a measure similar to the LCFS is under consideration in a regional consortium of eleven Northeastern and Mid-Atlantic States, which references California's LCFS and seeks to develop a regional LCFS program.

\section{The British Columbia Fuel Carbon Intensity regulations}

The Province of British Columbia introduced regulations designed to reduce the carbon intensity of road-transport fuels in its 2008 Greenhouse Gas Reduction (Renewable and Low Carbon Fuel Requirements) Act (RLCFR). ${ }^{26}$ Among other requirements, the RLCFR Act mandates minimum percentages of renewable-fuel contents in gasoline and diesel fuel imported to, or manufactured in, and used in

\footnotetext{
25. Office of the Governor of the State of California, Executive Order S-01-07.

26. www.bclaws.ca/EPLibraries/bclaws_new/document/ID/freeside/10_394_2008.
} 
the Province. ${ }^{27}$ The penalty for failing to incorporate the minimum amount of renewable fuel required is CAD 0.30 per litre shortfall for gasoline and CAD 0.45 per litre shortfall for diesel.

The Act also requires fuel suppliers to reduce the average carbon intensity (CI) - the grams of carbon-dioxide equivalent emitted per megajoule of energy consumed - of transportation fuels by $10 \%$ by 2020 , compared with the weighted average value of gasoline and diesel, including renewable-fuel content. ${ }^{28}$ The overall CI of fuels used for transportation is determined through a life-cycle assessment of all the emissions directly associated with fuel production and consumption, such as during the exploration and production of fossil fuels, the production of crops for biofuels and the refining, transport and end use of fuel, but not emissions linked to indirect land-use change. Suppliers can apply the default CI values provided in the regulation for the various types of fuel, or for each component of the GHG emissions computed by Canada's GHGenius model, or use an alternative method of determining CI if they can show it provides a more accurate value. Since 2010, fuel suppliers have been obliged to report annually on the CI of the transportation fuels they supply. Starting in 2012, they will be required to meet a decreasing average CI each year. Those who do not comply with this requirement will be subject to a monetary penalty of CAD 200 per tonne of $\mathrm{CO}_{2}$-equivalent in excess of their cap. The RLCFR allows transfers of GHG credits between fuel suppliers in order to provide flexibility in meeting the requirements of the regulation.

\section{Product-specific carbon footprint labels}

This group of initiatives includes requirements set by public authorities or private schemes (currently mainly focussing on food and beverages, household cleaning products, cosmetics and apparel) providing information on the GHG emissions generated over the full life-cycle, or a portion of the life-cycle, of a product. The private sector and more particularly retailers have been at the forefront of elaborating carbon-footprint assessments, certification and labels in order to respond to perceived consumer and shareholder demand for climatefriendly action, thus raising the environmental profile of their products and promoting sales, or to identify hot spots in their production chain where energy and associated GHGs can be reduced, thus lowering costs. To date, carbonfootprint labels have been essentially voluntary, even where they are actively promoted by governments, such as in the case of the UK Carbon Label. However, a mandatory requirement that consumer products indicate their carbon footprint (along with other information) is foreseen in France and is currently applied on an experimental basis.

This section discusses the planned French upcoming policy, as well as an illustrative sample of private voluntary carbon footprint labels for products. A large number of private GHG assessments and labels are performed at the level of

27. These are, for gasoline, a $5 \%$ renewable content beginning in 2010 , and for diesel a $3 \%$ renewable content in 2010, a $4 \%$ renewable content in 2011 , and a $5 \%$ renewable content from 2012 onward.

28. For 2011 only, the requirement was set to the default value of gasoline in order to make 2011 a reporting-only year. 
projects, corporations and corporate supply chains and participate in business' efforts to improve their corporate social responsibility image. These labels do not directly affect the marketing of specific products and are beyond the scope of a discussion focussing on PPM requirements. ${ }^{29}$ Likewise, private carbon-footprint labels in the form of compensation schemes, such as CarboNZero, or Certified CarbonFree, are not included in this review. These latter schemes indicate that the firm producing the product is carbon-neutral, because GHG emissions generated in the course of its commercial activities have been offset through reforestation, improvements in energy efficiency, use of renewable energy, or other carboncredit-conferring projects chosen by the producer. They may thus incorporate PPM considerations (e.g., relating to purchased raw materials) when calculating the firm's carbon footprint prior to determining the required offset, but do not contain PPM requirements for conferring the label.

\section{The French environmental footprint indications}

Requiring that all products and services sold in France display indications of their environmental footprint was one of the ideas that emerged from the Grenelle de l'Environnement, a political dialogue launched in 2007 to elaborate France's s future strategy as regards environmental protection and sustainable development. The Grenelle de l'Environnement led to the preparation of two pieces of legislation: Grenelle $1^{30}$, a framework law establishing the general principles of the government's environmental programme, and Grenelle $2^{31}$, which further specifies positive-law measures stemming from the framework law.

Article 54 of Grenelle 1 addresses consumption and the environmental impacts of products and services and calls for improving the environmental awareness of consumers. This is meant to be achieved by promoting awareness campaigns on sustainable development and energy efficiency; adapting advertising regulation to integrate environmental and sustainable-development considerations; and improving information available to consumers by requiring products and packaging to bear environmental information that is genuine, objective and complete. The regulator is invited to elaborate obligations on environmental impact labels, along with information on the origin and on the social conditions of production, and to develop the necessary impact-assessment methodology. These obligations are meant to be progressively extended to services. In parallel, in order to ensure that consumers are offered goods that are respectful of the environment at attractive prices, the regulator is invited to develop positive and negative price incentives for specific categories of products and to introduce VAT discounts for products with a lower impact on the environment.

\footnotetext{
29. However, requirements on suppliers of productive inputs imposed by corporate supply chains in order to achieve the commitments associated with a supply-chain label are discussed in the Section E starting on page 27.
}

30. Loi no 2009-967 du 3 août 2009 de programmation relative à la mise en auvre du Grenelle de l'environnement.

31. Loi $\mathrm{n}^{\circ}$ 2010-788 du 12 juillet 2010 portant engagement national pour l'environnement. 
In parallel, Operational Committee $23^{32}$ invited the government to support private initiatives to assess the environmental impact of different product categories, and to encourage voluntary initiatives to include information on social aspects within the supply chain of products (e.g. child-labour laws) to promote socially responsible production processes.

The framework engagements in Grenelle 1 are further specified in the Grenelle 2 legislation. Article 228 of the legislation elaborates on the requirement imposed on retailers to provide environmental information to consumers. The law, enacted in July 2010, introduced new measures into the French Consumer Code (Code de la Consommation). In particular, beginning 1 July 2011 and initially on an experimental basis, consumers are to be informed by way of marking, labelling, posting or any other "suitable" manner of the carbon-equivalent content of products and their packaging, as well as the consumption of natural resources or the environmental impact during the life cycles of those products. Taking stock of the experiment's outcomes, the administration will report to the Parliament as to whether the environmental information requirement should be generalised. The specific conditions for the implementation of this requirement and for measuring carbon footprint and other environmental impacts would then be set by decrees of the State Council. These conditions will vary depending on the affected category of products, taking into account their distribution mode and the capacity of small and medium enterprises (SMEs) to provide the required information to consumers. It is as yet not specified whether this requirement will bear on producers, retailers or both and how it will be implemented in the case of imported products.

The provisions relating to environmental information also require that advertising on products subject to mandatory energy-performance labelling shall display the energy class of the products in a way that it is as visible, readable and understandable as the selling price. In addition, where marketed products, or their packaging, advertising or commercial leaflets contain environmental claims or use the term "sustainable development" or its synonyms, they shall be subject to requirements for accuracy, verification, and consideration of the product's life cycle. These requirements will be defined by means of State Council decrees.

Finally, the new regulations require providers of transport services (for people, goods, and relocation of households) to inform consumers of the quantity of carbon dioxide emitted by the transport method used for that service. The coverage and implementation modalities, including the timetable and methods for calculating emissions and providing the information will be laid down by decree.

The government is in the process of developing: a) a standardised methodological framework; b) ways to communicate environmental information for assessing the environmental impact of different products; and c) a public LCA database, to ensure comparability of the estimates within and among different product categories. The public database, managed by ADEME, ${ }^{33}$ will be open to

32. Thirty-three Operational Committees on various themes were set up to develop the framework for implementing Grenelle's 268 conclusions. OC23 focussed on consumer issues.

33. Agence de l'Environnement et de la Maitrise de l'Énergie (Environment and EnergyManagement Agency). 
both public and private contributions. The development of the LCA method and of the guidelines for communication was entrusted to a joint ADEME/AFNOR ${ }^{34}$ platform, which was also invited to design a universally comparable standard so as to prevent growing disparities among private voluntary initiatives.

The LCA method is being developed in accordance with the International Organization for Standardization's standards for life-cycle assessment, ISO 14040 and ISO 14044, while the communication format for environmental indications will comply with the ISO 14020 series of standards on environmental labelling. For the production phase, the assessment will be based on the energy model of the producing country, while for the use phase it will be based on the French energy model. Data for the energy use in production will be included in the public database and based on the calculation of carbon emissions and other impacts from electricity production (per kilowatt-hour) over the past three years. The environmental impact of transportation will be evaluated from the distance, the transport mode and equipment, fuel use, the capacity factor of the transport mode, and the empty-return ratio of the transport mode. Information on emissions generated by customers in travelling to the product or store will also be made available to the consumer, but will not be included in the estimates of the lifecycle carbon emissions that are displayed. The impact of a product's end-of-life stage shall take into account the rate of recycling, energy recovery, and final disposal as landfill waste. Considering the difficulties for SMEs to conduct appropriate LCAs to generate the required data, the work is also focussing on the development of simplified assessment tools for use by these firms.

The LCA method will include sectoral rules for various product categories, ${ }^{35}$ including but not limited to GHG effects. These rules are being developed by specialised Working Groups and tested in pilots. The Working Groups seek to measure the impacts in terms of a single use of the product; for example, the GHG emissions of detergents will be indicated to the customer in grams of $\mathrm{CO}_{2}$ equivalent per wash.

\section{Private schemes and labels}

Private labels displaying carbon footprint information for specific products ("product carbon footprints" or PCFs) can be categorised as follows: labels displaying the calculated PCF, with or without a benchmark or reference value, such as the French Casino Carbon Index, the Canadian CarbonCounted logo, or the US Climate Conscious label; labels displaying the calculated PCF together with the planned or achieved reduction to this footprint in the form of numerical values, or as a commitment to reduce, such as the Carbon Reduction Label; labels

34. Association Française de Normalisation (French Standards Association).

35. The defined product categories are food and pet food; hardware and equipment, batteries and accumulators; cleaning products (e.g. detergent), garden products and pesticides; hygiene and beauty; clothing, home textiles, footwear, and leather; building products, decorations, paints, glues and varnishes; furniture; stationery, publishing, entertainment, culture, writing materials; tableware and kitchenware; sports equipment, camping equipment, mobility equipment, games and toys; non-electrical tools and hardware; financial services (banking and insurance); cars and motorcycles; jewellery and silverware; spare parts of automobiles; and musical instruments. 
indicating that the product enjoys one of the best PCFs in its category of products, without providing the footprint figures themselves, such as the Swiss Climatop label; and labels indicating that the product is GHG-neutral because the carbon footprint generated by the product is offset, such as the CarboNZero or Certified CarbonFree ${ }^{\circledR}$ labels (this category will not be reviewed here). Private labels focus quite extensively on agrifood products, but manufactured goods, such as clothes, footwear, cell phones, or consumer appliances are also covered. The description below does not review all existing private PCF schemes and labels, but rather some representative examples of the first three categories above.

These first three categories of labels base their carbon-footprint calculations on life-cycle assessments, including an assessment of the products' processes and production methods. Given the features of existing calculation methodologies and available data, labels displaying precise carbon-footprint values are generally approximations to footprint values rather than fully accurate calculations with no margin of error. The accuracy of comparative, "best-of-class" labels depends on the basis for comparisons: the broader the sample of products, the more reliable the comparison (as a limited basis for comparison would risk ignoring better or worse performing products. Comparability of figures or assertions among schemes depends on the use of a common pool of data and a harmonised methodology across countries, types of products and corporate supply chains. In fact, different schemes may not always rely on the same notions and factors for the purposes of calculating carbon footprints: e.g. the notion of "life-cycle" is not always equivalent in different schemes, with boundaries excluding in some cases upstream stages, such as the production of capital goods, and in others downstream stages, such as the transport to the point of consumption, while some schemes lack a clear and detailed description of what is actually covered.

\section{Examples of quantitative carbon footprint labels: the Casino Carbon Index}

The Casino Carbon Index (Indice Carbone) is the proprietary label for Groupe Casino, a major French retail group. It was developed by an environmental consultancy, Bio Intelligence Service, in 2006 on the basis of a retail distribution specific methodology validated by ADEME and implemented by Casino since 2008. The collection of data on Casino-brand supply chains was launched in January 2007, covering 150 direct suppliers and more than 600 Casino-brand products. GHGs other than $\mathrm{CO}_{2}$, such as nitrous oxide $\left(\mathrm{N}_{2} \mathrm{O}\right)$, are taken into account and translated into $\mathrm{CO}_{2}$ equivalents for ease of reference. In the absence of specific data for each product, Casino uses data from generic life-cycle analyses on the environmental impact of production and manufacturing stages. The label, displayed on the front side of the package and symbolised by a green leaf, indicates the calculated carbon footprint for the product expressed in grams of $\mathrm{CO}_{2}$ per $100 \mathrm{~g}$ of product. On the back side of the product the index is shown as a green band giving the position of the environmental impact of the product on a scale of levels (from weak impact to strong impact). The graduations of the scale are fixed in partnership with ADEME, but no explanation is provided on the label or the website as to how the benchmarking was calculated. 
Casino's website ${ }^{36}$ explains that the calculation of $\mathrm{CO}_{2}$ emissions of the product takes into account the following life-cycle phases: (1) the various stages of agricultural production of foodstuff ingredients, including the manufacturing of phytosanitary products used, energy consumption and general functioning of the farm; (2) the manufacturing of the product, including the type and location of the factory and its energy consumption ${ }^{37}$; (3) packaging issues, from those used for raw materials, to packaging of the final product, to final disposal or recycling, taking into account both weight and type of materials; (4) the transport of raw materials, packaging and final products from the field to Casino warehouses, taking into account the various transport modes; (5) the distribution from Casino warehouses to the consumer's home, including warehouse and transport energy consumption and refrigeration needs. The use phase and end-of-life are not included, except for the product's packaging. The quantitative impact information is valid for mainland France only. Currently more than 500 products of the Casino brand are already labelled and Casino plans to ultimately label all 3000 of the food products it offers for sale.

\section{The CarbonCounted logo}

The CarbonCounted logo was developed by CarbonCounted, a Canadian nonprofit organisation, as a complement to their online carbon-footprint calculator, CarbonConnect. The calculator can be used by businesses to track, quantify and manage GHG content throughout their supply chain. GHG emissions can be calculated on the basis of lifecycle analysis, including the harvesting, extraction and production phases, but concerned businesses can also choose to measure emissions with the GHG Protocol method instead, i.e. use average national economic and environmental impact data, rather than company-specific processes or practices, to estimate the amount of GHGs embedded in a given product. Most companies carrying the CarbonCounted logo have currently opted for the latter approach. Each company using the CarbonConnect calculator have to submit their PCF assessments to an annual independent verification by CarbonCounted certified auditors, generally, but not exclusively, on the basis of the GHG Protocol, ISO 14064 (GHG inventories and reporting), ISO 14025 (environmental labelling directions) and PAS 2050. Following this verification the company can display the CarbonCounted logo indicating the product's $\mathrm{CO}_{2}$ equivalent. Currently 40 companies carry the logo.

\section{The Climate Conscious label}

The Climate Conscious label was developed by The Climate Conservancy (TCC), a US non-profit organisation founded by scientists at Stanford University, in order to provide information about the GHG emissions of consumer goods. The label rates products in terms of their GHG intensity, i.e. the grams of $\mathrm{CO}_{2}$ equivalent emissions per dollar of product (retail value), developed to allow comparisons among products, including similar ones within an economic sector, over time. The Climate Conscious label uses a process-specific LCA

\footnotetext{
36. www.groupe-casino.fr/fr/Un-nouveau-repere-pour-acheter.html.

37. In order to calculate the energy consumption per unit of product, the annual energy consumption of a factory is divided by the total volume of its production.
} 
methodology to document GHG emissions throughout the value chain of the product. Moving away from entity-level inventories, which do not allow comparisons between specific products, the assessment focuses on the complete life-cycle of the product, including production of all raw and manufactured materials, conversion of those materials into a finished product, processing of waste, product packaging, any storage and transportation of products, in-use emissions and disposal or recycling of the product. It incorporates also immediate offset projects of the company. ${ }^{38}$ The TCC is involved as a reviewer in the development of the PAS 2050, but until a single standard for product-level GHG inventories is finalised, it uses its own method, summarised on the TCC website. The assessed product's GHG intensity is rated against the GHG intensity of the average product in the same economic sector and labelled with a performance rating rather than displaying a specific $\mathrm{CO}_{2}$ content (silver for emission reductions of $10-40 \%$, gold for reductions of $41-70 \%$, and platinum for reductions of $71 \%$ or greater). The dynamic baseline of the calculation allows the label's metric to follow the progression towards a low-carbon economy.

\section{An example of a reduction commitment label: the Carbon Reduction Label}

The Carbon Reduction Label was developed in 2007 by the Carbon Trust, a not-for-profit UK company, in co-operation with the UK Department for Environment, Food and Rural Affairs (DEFRA) and BSI British Standards. Carbon Trust's methodology is based on the PAS 2050 meta-standard and was originally piloted with Walkers crisps, Boots shampoo and Innocent Drinks fruit smoothies and then trialled by 20 companies prior to its launch. ${ }^{39}$ The label, displayed on the package of the product, or presented at points of sale, sales catalogues and websites, indicates the product's calculated carbon footprint, an average carbon footprint for the overall product group to provide context for comparison, and informs about the brand's commitment to reduce the product's footprint over the following two years. The label shows the total greenhouse-gas emissions $^{40}$ in grams per indicated functional unit (for instance $360 \mathrm{~g}$ per $250 \mathrm{ml}$ serving of pure squeezed orange juice), taking into account every stage in the product's lifecycle, including the raw materials and packaging needed to produce it, through to manufacture, transportation, sale to the end user, use and disposal. This applies to consumer products, while for intermediate products the calculation is done only cradle-to-gate. Furthermore, information can be given on the label concerning the comparison to other products and the possibilities for consumers to reduce the PCF by their behaviour.

The PCF is measured directly by the brand, or by environmental consulting firms on behalf of the brand, using Footprint Expert ${ }^{\mathrm{TM}}$, a Carbon Trust toolkit. The toolkit, available to licensed users, helps establish a process map, collect primary data from members of the supply chain and collate secondary data. It includes pre-built carbon calculators for common emissions "events"

38. See for instance a product case study "The Carbon Footprint of Fat Tire ${ }^{\circledR}$ Amber Ale, displayed on www.climateconservancy.org/cca fattire.pdf.

39. The PAS 2050 was officially launched in 2008 and it now available without charge for public use around the world.

40. Expressed in $\mathrm{CO}_{2}$ equivalents for simplicity. 
(e.g. transport or refrigeration), a model framework providing a template for footprint measurement, and a reference database containing country-specific emissions factors for common processes and commodities. The calculated footprint is then checked by the Carbon Trust Footprinting Certification Company, which applies a set of proprietary data and comparability rules to certify compliance with the PAS 2050, so as to ensure that consumers can compare similar products and services against one another. The brand has to commit to reducing the product's emissions. Every two years, the product must be reassessed and the label is removed if the committed reduction has not been achieved. The Carbon Reduction Label has certified more than 5000 products since 2007 and is now used by companies such as Cemex, DuPont, Dyson, LG, PepsiCo and Tesco and is gaining ground outside the United Kingdom in Europe, Asia, Australia, New Zealand and the Americas.

\section{An example of a comparative carbon-footprint label: the Climatop label}

Climatop was founded in 2008 by two Swiss not-for-profit organisations, Ökozentrum Langenbruck and Myclimate, with a view to establishing a climatefriendly product label, "Approved by Climatop". The Climatop label indicates that the product belongs to the most climate-friendly in its class of products but it does not display any PCF figures. The criterion for awarding the label is not the absolute value of $\mathrm{CO}_{2}$, but the $\mathrm{CO}_{2}$ emissions compared with a relevant group of substitute products. In order to enable the comparisons that form the basis of the label, Climatop has performed LCAs of GHG emissions for over 100 products within nine product groups, based on the $\mathrm{CO}_{2}$ balancing data of Ecoinvent. ${ }^{41}$ The LCA studies have been submitted to critical reviews by an environmental consultancy. Assessments cover stages from the exploitation of the raw material, the manufacturing processes and energy supply, the transportation up to the consumption point, and finally waste disposal.

The average lifetime of the product and its recycling alternatives are also considered. Brands wishing to use the Climatop label have to prove that the products concerned emit at least $20 \%$ less $\mathrm{CO}_{2}$ than substitute products reviewed by Climatop, and their assessment is then verified and certified independently by Climatop. In addition, the product has to fulfil several other requirements relating to environmental and social standards. The label is valid for two years. Climatop provides on its website factsheets and critical reviews of LCA studies on which the assessments are based, so that consumers can have access to background data on the range of PCF of different products within one product group. The Climatop label coverage is gradually increasing, including now 49 product types with over 100 articles from ten suppliers, including Dyson and Migros.

41. Formerly the Swiss Centre for Life Cycle Inventories, a not-for-profit entity created in 1997 by the Swiss Federal Institute of Technology Zürich (ETH Zurich) and Lausanne (EPF Lausanne), the Paul Scherrer Institute ( $\underline{\mathrm{PSI}})$, the Swiss Federal Laboratories for Materials Testing and Research (Empa), and the Swiss Federal Research Station Agroscope Reckenholz-Tänikon (ART). 


\section{Preferences in government procurement relating to life-cycle environmental impacts}

This group of policies includes government procurement regulations or specific terms in calls for tender that give preference to goods or services with relatively low environmental footprints. Green public procurement regulations are more and more common in the OECD area and beyond. At the regulatory level, few non-product-related PPM provisions can be found. Indeed, it is often the case that regulations do not directly include PPM provisions, but rather enable procuring entities to rely on PPM criteria in the terms of reference of specific calls for tender. Climate-change-related provisions in regulations focus essentially on product characteristics, including calls to base procurement decisions on what they term operational life-cycle assessments (i.e. LCA limited to the consumption and disposal phase, excluding production), such as for vehicle purchases (see for example Japan's Law concerning the promotion of procurement of eco-friendly goods and services by the State and other entities, or EU Directive 2009/33, which requires EU public authorities to take account of the lifetime costs and emissions from vehicles in their procurement procedures). Many of these productrelated regulations are based on existing eco-labelling schemes in order to identify goods or services eligible for green-procurement preferences.

This paper focuses on regulatory provisions rather than the use of climaterelated criteria by procuring entities in the context of their tendering activities. The few existing PPM general regulatory requirements for low-carbon procurement are built around sustainability criteria. Approaches to defining "sustainability" are as diverse as in other climate-change regulations, and government-procurement provisions mostly refer to sustainability criteria more generally applicable in climate-change regulations.

\section{The US preference for procurement of alternative fuels}

The US Energy Independence and Security Act (EISA, see above), includes a series of provisions on energy pertaining to federal agencies. Among them, Section 526 directs federal agencies to introduce lifecycle GHG emissions requirements in all contracts for procurement of alternative fuels. Procurement contracts should specify that lifecycle GHG emissions associated with the production and combustion of the alternative fuel supplied must, on an ongoing basis, be less than or equal to such emissions from the equivalent fuel produced from conventional petroleum sources. The definition of life-cycle GHG emissions introduced in EISA Sec. 201 for the RFS program also applies here. This provision should be read in conjunction with requirements in federal and State regulations ${ }^{42}$ concerning the purchase by federal agencies of alternative-fuel vehicles and setting volumetric targets for the use of alternative fuels.

42. Section 701 of EPAct, and executive Order 13423, as well as State regulation in Iowa, Illinois, Kentucky and New York. 


\section{EU green-procurement provisions}

Provisions on green procurement can be found in the EU regulatory framework for public procurement. ${ }^{43}$ Green public procurement covers areas such as the purchase of energy-efficient computers and buildings, office furniture made from environmentally sustainable wood products, recyclable paper, electric cars, public transport, organic food served in canteens, electricity from renewable energy sources, and air-conditioning systems complying with state-of-the-art environmental criteria. The two Directives provide a sound-procurement-process framework for co-ordinating procedures in EU Member States, and do not contain substantive provisions about procurement preferences, but they allow the incorporation of PPM requirements in public procurement.

Contracting authorities can take into account environmental characteristics by introducing environmental performance criteria $^{44}$ in any stage of the tender process, from the technical specifications to the award criteria. They can also introduce environmental requirements in the conditions for the performance of the contract. Technical specifications relating to environmental performance may be formulated as PPM requirements. In order to formulate these requirements, contracting authorities can (but are not obliged to) use appropriate specifications that are defined in existing eco-labels, provided that the requirements of the label are drawn up and adopted through a stakeholder participatory mechanism on the basis of scientific information, and are accessible to all interested parties. In such a case, contracting authorities may indicate that products bearing an eco-label are presumed to comply with relevant technical specifications, but they must accept any other appropriate means of proof.

The 2008 Commission communication on public procurement for a better environment ${ }^{45}$ calls for production-related criteria to be measurable and verifiable so as to treat bidders in the same way and allow effective verification of bids against tender documents. The EU Handbook on environmental public procurement ${ }^{46}$ explains that, as all technical specifications should bear a link to

43. Directive 2004/18/EC of the European Parliament and the Council of 31 March 2004, on the coordination of procedures for the award of public works contracts, public supply contracts and public service contracts. Directive 2004/17/EC of the European Parliament and the Council of 31 March 2004 coordinating the procurement procedures of entities operating in the water, energy, transport and postal services sectors.

44. Common Green Public Procurement criteria have been developed in the framework of a European Commission "Training toolkit" on GPP. They cover 18 product and service groups and works (45 products all together): Construction, Food and catering services, office IT equipment, gardening products and services, transport, electricity, cleaning products and services, textiles, furniture, copying and graphic paper, windows, thermal insulation, wall panels, hard floor-coverings, cogeneration equipment (CHP), road construction and traffic signs, street lighting and traffic signals, and mobile phones (see ec.europa.eu/environment/gpp/gpp_criteria en.htm).

45. Public Procurement for a Better Environment, Communication for the Commission to the European Parliament, the Council, the European Economic and Social Committee and the Committee of the Regions, COM(2008)400 final.

46. Buying Green! A handbook on environmental public procurement, European Commission services, 2004. 
the subject matter of the contract, "only those (PPM) requirements which are related to the manufacturing of the product and contribute to its characteristics, without necessarily being visible" can be included. The relevant "characteristics" are thus not only physical characteristics, and may include factors that are closely linked to the production of the product at stake while not resulting in any physical features: for instance, criteria relating to the sustainable management of natural resources can be used as procurement specifications. Similarly, it is possible to ask for electricity to be produced from renewable energy sources, as it is considered that the method of production has modified the nature and value of the end product. In order to provide a reliable method of proof of PPM compliance, Article 15 of the EU Renewable Energy Directive ${ }^{47}$ requires Member States to ensure that the origin of electricity from renewable energy sources can be guaranteed according to objective, transparent and non-discriminatory criteria. Guarantee of Origin schemes are not exclusive proof and the supplier can provide independent proof that a corresponding quantity of electricity has been generated from renewable sources, such as a tradable certificate from an independent issuing body.

The EU Energy Efficiency Directive ${ }^{48}$ invites the public sector in each Member State to set a good example regarding investments, maintenance and other expenditure on energy-using equipment, energy services and other energyefficiency improvement measures and to use energy-efficiency criteria in tendering procedures for public procurement. However, although the Directive invites Member States to publish guidelines on energy efficiency and energy savings as a possible assessment criterion in competitive tendering for public contracts, this mainly focuses on energy-efficient product specifications.

\section{Swiss sustainable procurement recommendations}

The Swiss Federal Procurement Commission (BKB) has issued in November 2010 a set of Recommendations to the Procurement Services of the Confederation in favour of Sustainable Procurement ${ }^{49}$, in order to guide procurement services in incorporating environmental or social concerns, while ensuring value for money in public purchases. The Recommendations recall that Swiss procurement legislation (1994 Federal Law on Public Procurement LMP 172.056.1) does not allow for environmental considerations to be used as a condition for participating in a tender and advises procuring authorities against using them to exclude potential bidders from the tendering process. On the other hand, environmental considerations can and should be taken into account when defining the technical specifications of the procured goods and services and the criteria for adjudicating a tender. They can also be introduced among the contract requirements once the successful bidder has been identified. In particular, technical specifications can include the production method of the procured good, in so far as the method bears a link to the subject matter of the contract. This does not necessarily mean that the

47. Directive 2009/28/EC, see above.

48. Directive 2006/32/EC of the European Parliament and the Council of 5 April 2006 on energy end-use efficiency and energy services, Article 5 and Annex VI.

49. Recommandations aux services d'achat de la Confédération en faveur d'achats durables, available on www.bbl.admin.ch/bkb. 
production method should visibly affect the physical characteristics of the product, but "it should at least modify the product's value and special features". The Recommendations offer a series of examples, including electricity produced from renewable energy sources.

\section{Carbon footprint requirements in corporate supply-chain schemes}

Non-product-related PPM requirements can also be found in the framework of private GHG labels and reduction schemes for corporations and corporate supply chains. These PPM requirements are imposed by the concerned corporations on the suppliers of productive inputs, such as raw materials and intermediate goods. They aim at influencing the productive stages upstream from the corporation's direct control, as required by the life-cycle approach of the label or reduction scheme. Such requirements are applied on a voluntary basis by the concerned corporations, but they may have significant market impacts in particular for affected suppliers, whose practices may need to be adjusted if they wish to maintain business relations with the client corporation.

\section{An example of requirements in corporate supply chain schemes: Timberland's Climate Strategy}

Timberland's Climate Strategy includes an endeavour to "leverage(e) relationships with partners in (their) footwear value chain to reduce climate impact". Carbon emissions from the company's value chain, including raw materials and finished-product factories, represent approximately $96 \%$ of the carbon footprint associated with the company's business ${ }^{50}$, around $72 \%$ for the former and $24 \%$ for the latter. These considerations pushed Timberland to include in their climate strategy initiatives to reduce the carbon impacts of the value chain through design and material sourcing. They are complemented by a proprietary label, the Green Index ${ }^{\mathrm{TM}}$, which measures GHG emissions produced from rawmaterial extraction through finished products at the factory, in addition to two other environmental factors, the use of hazardous chemicals, and the consumption of resources other than recycled, organic and renewable materials. In addition to material selection and product recycling, the company has set a Code of Conduct to help manage emissions at factories assembling finished products. Code of Conduct assessors track value-chain emissions in those factories and provide consulting to encourage the adoption of environmentally preferred behaviours. Data collected from the assessors on the factories' emissions are displayed in the company's quarterly reporting. In 2006 Timberland launched the Leather Working Group Environmental Assessment in co-operation with other concerned brands, with a view to addressing impacts from raw-material suppliers. The Group produced a common scorecard that measures tanners' environmental performance in over 300 areas, including energy use.

50. The remaining $4 \%$ corresponds to the emissions of the facilities Timberland owns and operates (offices, distribution centres, retail locations and a manufacturing facility in the Dominican Republic), as well as employee travel. As part of its corporate social responsibility strategy, the company set a Carbon Neutral goal for these operations by 2010 . 


\section{Concluding remarks}

This initial survey of existing climate-change mitigation regulations reveals that provisions focussing on non-product-related PPMs exist in a number of climate-change regulations, although by no means in the majority of them. Most of these PPM-based requirements relate to the sustainability characteristics of PPMs, which generally rely on life-cycle assessments but are defined and calculated in quite a different manner in various countries. Fewer of these requirements focus on GHG-emission characteristics. Preferences in government procurement based on PPM characteristics are rare in regulations and are generally applied in the context of specific calls for tender. Mandatory carbonfootprint labels are still in an experimental stage.

Although the regulatory objectives are similar across the reviewed regulations (e.g. promotion of renewable energy sources, while seeking to avoid other harmful consequences on the environment), the choice of instruments varies considerably: some rely more or less extensively on market mechanisms, others introduce command-and-control provisions limiting the use of certain PPMs, while yet others target certain types of fuels for support. None, however, goes as far as to require the mandatory use of a specific PPM. All of the reviewed regulations are fairly new and the experience with their application has been quite short. PPM provisions can also be found in a number of private-sector labels and schemes for climate-change mitigation, generally in the form of product carbonfootprint labels or GHG-related requirements for suppliers of productive inputs. Private schemes are also fairly recent and are still working their way through problems of data and methodology and the challenge of capturing sufficient consumer attention. Their trade impacts in the domestic and global markets are still limited but could grow significantly in the future. 


\section{References}

Appleton, Arthur (2009), "Private climate change standards and labelling schemes under the WTO Agreement on Technical Barriers to Trade", in T. Cottier, O. Nartova and S.Z. Bigdeli (eds.), International Trade Regulation and the Mitigation of Climate Change, Cambridge University Press for the World Trade Forum, Cambridge, UK.

California Air Resources Board (2009, October), California's Low Carbon Fuel Standard, Sacramento, California, available at www.arb.ca.gov/fuels/lcfs/100609lcfs_updated_es.pdf.

Carbon Trust (2008), Product Carbon Footprinting: the new business opportunity. Experience from leading companies, London, UK.

The Climate Conservancy (2007), Methodology Summary of the Climate Conscious Assessment, available at www.climateconservancy.org.

The Climate Conservancy (2008), The Carbon Footprint of Fat Tire ${ }^{\circledR}$ Amber Ale, available at www.climateconservancy.org/cca_fattire.pdf.

Climatop, Factsheets for Licensed Products, available at: www.climatop.ch/index.php? $1=e \& p=$ products Anbieter.

De Gorter, Harry and David R. Just (2009), "Why sustainability standards for biofuel production make little economic sense", CATO Policy Brief, No. 647, 7 October 2009, available at www.cato.org/pubs/pas/pa647.pdf.

Earley, Jane (2009), US Trade Policies on Biofuels and Sustainable Development, ICTSD Issue Paper $n^{\circ} 18$, June 2009.

Green, Andrew (2005), "Climate Change, Regulatory Policy and the WTO: How Constraining Are Trade Rules?”, Journal of International Economic Law, Vol.8, n 1.

Hodgson, Ian (2008), Proposed EU Low Carbon Fuel Standard, ppt presentation, European Commission, Brussels, available at: www.theicct.org/documents/Hodgson_Proposed_EU_LCFS_HK.pdf.

Moïsé, E. (2011), “Transparency Mechanisms and Non-Tariff Measures: Case Studies”, OECD Trade Policy Working Papers, No. 111, OECD Publishing, Paris. http://dx.doi.org/10.1787/5kgf0rzzwfq3-en.

OECD (1994), Trade and Environment: Processes and Production Methods, OECD Publications, Paris.

OECD (1997), "Processes and production methods (PPMs): conceptual framework and considerations on use of PPM-based trade measures", OCDE/GD(97)137, OECD Publications, Paris.

OECD (2001), "Flagship Report on Regulatory Quality", internal working document, Public Management Service, OECD, Paris.

OECD (2009), "Counting Carbon in the Market Place", internal working documents, Trade and Agriculture Directorate and Environment Directorate, OECD, Paris. 
OECD (2010), "Transparency Mechanisms and Non-Tariff Measures: Case Studies", Trade Policy Working Paper No. 111, OECD, Paris.

Potts, Jason (2008), The Legality of PPMs under the GATT: Challenges and Opportunities for Sustainable Trade Policy, International Institute for Sustainable Development, Winnipeg, Manitoba, Canada.

Quack, Dietlinde (2010), "Requirements on Consumer Information about Product Carbon Footprint", Final Report, Öko-Institut e.V., commissioned by ANEC, the European consumer voice on standardisation, February 2010

Read, Robert (2005), "Process and production methods and the regulation of international trade", in Nicholas Perdikis and Robert Read (eds.), The WTO And The Regulation Of International Trade: Recent Trade Disputes, International Economics Study Group, pp. 239-236, available at www.lancs.ac.uk/people/ecarar/ppms.doc

Regan, Donald (2009), "How to think about PPMS and climate change", in T. Cottier, O. Nartova and S.Z. Bigdeli (eds.), International Trade Regulation and the Mitigation of Climate Change, Cambridge University Press for the World Trade Forum, Cambridge, UK.

Roundtable on Sustainable Biofuels (2010), Introduction to the RSB Certification Systems, RSB Technical Report.

Sperling, Daniel and Sonia Yeh (2009), "Low carbon fuel standards", Issues in Science and Technology, Winter, pp. 57-66.

Swinbank, Alan (2009), EU Support for Biofuels and Bioenergy, Environmental Sustainability Criteria, and Trade Policy, ICTSD Issue Paper n ${ }^{\circ}$ 17, June 2009.

Timberland (2009), Timberland Climate Strategy, 2009 Report.

Torney, Diarmuid and Moustapha Kamal Gueye (2009), Climate Change Mitigation Policies in Selected OECD Countries: Trade and Development Implications for Developing Countries, ICTSD Issue Paper $n^{\circ}$ 8, December 2009.

United Nations Department of Economic and Social Affairs (2008), Public Procurement as a Tool for Promoting more Sustainable Consumption and Production Patterns, Sustainable Development Innovation Briefs, Issue 5, August 2008.

Zarrilli, Simonetta and Jennifer Burnett (2009), "Certifying biofuels: benefits for the environment, development and trade?", in T. Cottier, O. Nartova and S.Z. Bigdeli (eds.), International Trade Regulation and the Mitigation of Climate Change, Cambridge University Press for the World Trade Forum, Cambridge, United Kingdom. 